\title{
Hyperimmunoglobulin M Syndrome
}

National Cancer Institute

\section{Source}

National Cancer Institute. Hyperimmunoglobulin M Syndrome. NCI Thesaurus. Code C3990.

An immunodeficiency state characterized by very low serum Ig G and IgA but either a normal or, more frequently, a markedly elevated concentration of polyclonal IgM. 